\title{
Benefits of Network Security and Mass Communication Systems for Journalism Education in Nigeria
}

\author{
Joseph Oluchukwu Wogu ${ }^{1}$ and Christian Alozie Ogbonna ${ }^{1 *}$ \\ ${ }^{1}$ Department of Mass Communication, University of Nigeria Nsukka \\ *ogbonna.aloziechristian@gmail.com
}

\begin{abstract}
Digitization has transformed people's lifestyles, work, learning, and demand for services as well as the way organizations operates their day-to-day activities. As a result of malicious users, any agency or institution that desires to offer services that consumers require has to secure its computer network. Network security can enable organizations to guard proprietary information against being attacked. This paper highlights some types of network security for use by mass media organizations as well as some of the mass communication systems in today's media world. With an emphasis on network security and mass communication systems, the authors argued that journalism education in Nigeria can be redefined to help minimize the spread of misinformation across multiple media platforms. This paper, thus, recommends additional research in the aspects of the effectiveness of journalism education in relation to mass communication systems, multimedia journalism, the problems and needs of media institutes, network security of the Nigerian media, and digitalisation policy of journalism and mass communication institutes in Nigeria.
\end{abstract}

Keywords: Digitization, Network Security, Mass Communication Systems, Journalism Education, Nigeria

\section{Introduction}

\subsection{Network Security}

Digitization has transformed the globe including how people live, work, learns, and consumes services as well as the way organizations operate their day-to-day activities. Due to malicious users, any organization including the media that desires to provide services that consumers require has to secure its computer network. Network security is any action, policy and practices adopted to protect the usability and integrity of computer network, data and resources and includes both hardware and software technologies. The maintenance of effective network security helps manage access to the network and targets a diversity of threats and stops them from entering or spreading on the network. Network security incorporates multiple layers of defenses at the edge and in the network and each network security layer implements policies and controls. Therefore, authorized users gain access to network resources, whereas, malicious intruders are blocked from carrying out exploits and threats. Network security can help an organization protect proprietary information from attack (Cisco, 2018). In turn, it can safeguard the social and economic reputation of an organization which uses mass communication systems. Therefore, a discussion of the different types of network security which can be adapted for use by mass media organizations for multimedia journalism is of paramount interest to the authors of

Received (January 19, 2018), Review Result (May 10, 2018), Accepted (May 16, 2018)

* Corresponding Author 
this paper. Deducing from Cisco (2018), the following are some types of network security for use by mass media organizations:

1.1.1. Network Access Control: Network access control requires that all users are not allowed access to an organization's entire computer network. In order to keep out possible attackers, media organizations have to recognize each user and each device, be able to enforce their security policies, and block noncompliant endpoint devices or give them only limited access.

1.1.2. Antivirus and Anti-Malicious Software: It is important to note that malicious software like viruses, ransomware, Trojans, worms, and spyware which at times infect a network while staying latent for days or even weeks. Conversely, anti-malicious software programs are programs which do not only scan for malicious software upon entry but also constantly track files afterwards to locate anomalies, get rid of malicious software, and repair damage.

1.1.3. Behavioral Analytics: Media organizations can use behavioral analytics tools to routinely detect activities that stray from normal network behavior. A media organization's network security team can help spot indicators of compromise that create a latent problem and swiftly remediate threats to their computer network.

1.1.4. Application Security: Media applications may have holes or vulnerabilities which attackers can use to infiltrate a media organization's network. Thus, it is important to deploy application security which encompasses the software, hardware, and processes used to seal such holes by media organizations.

1.1.5. Web Security Solution: Web security describes the steps an organization takes to guard their website. A web security solution control staff's web utilization, prevents webbased threats, and counteract access to malicious websites. A web security solution can guard an organization's web gateway on site or in the cloud.

1.1.6. Email Security: Email entryway is the foremost threat vector for a breach of network security. In fact, network security attackers utilize personal information and social engineering strategy to create sophisticated phishing campaigns to trick recipients and redirect them to sites serving up malicious software. However, an email security application can be used by media organizations to wedge incoming attacks and manage outbound messages to avoid the loss of data and information which are responsive.

1.1.7. Mobile Device Security: Given that there are many cybercriminals on daily basis aim at posing big threats to mobile devices and apps usage, media organizations have to seek for ways to be support their corporate applications of mobile devices in information dissemination. Media organizations need to be in charge of which devices can access their network. They also need to configure their connections to keep network traffic private.

1.1.8. Wireless Security: Wireless networks are not very secured when compared to wired networks. In the absence of a rigorous security measures, installing a wireless LAN can be security-drowning. In order to avert security breaches, media organizations require products exclusively designed to guard a wireless network.

1.1.9. Data Loss Prevention: Media organization should realize that data loss prevention can help prevent individuals from uploading, forwarding, or printing crucial information in an insecure way. Thus, media organizations must ensure that their staff are tutored regarding dissemination of information within and outside the network. 
1.1.10. Firewalls: It is important to note that firewalls can create a barrier between an organization's trusted internal network and untrusted outside networks, like the Internet by utilizing a set of established rules to permit or wedge traffic. Firewalls could be in form of hardware, software, or both (see Cisco, 2018). Media organizations may opt in for the unified threat management devices and threat-focused next-generation firewalls developed by Cisco.

1.1.11. Intrusion Prevention Systems: An intrusion prevention system scans network traffic in order to actively block attacks. Media organization can opt-in for appliances which can help them achieve this. There are appliances which link vast number of worldwide threat intelligence to obstruct malicious activity and track the development of suspected files and malicious software across the network to stop the spread of outbreaks and re-infection.

1.1.12. Network Segmentation: The use of network segmentation ensures that network traffics are placed in various classifications. It also makes the enforcement of network security policies unproblematic. In practical terms, the classifications are not just based on an internet protocol address but also on endpoint identity. Thus, media organizations can assign access rights based on role, location, and ensure that the right level of access is given to the right people and suspicious devices are contained and remediated.

1.1.13. Security Information and Event Management: Security information and event management products bring together the information that an organization's network security staff require in order to recognize and respond to network security threats. The security information and event management products are available in different formats like physical and virtual appliances and server software.

1.1.14. Virtual Private Network (VPN): A virtual private network encrypts the connection from an endpoint to a network, often over the Internet. Usually, a remoteaccess VPN uses IPsec or Secure Sockets Layer to authenticate the communication between device and network.

\subsection{Mass Communication Systems}

The mass media are different forms of media technologies that are designed to get to a huge number of audiences through mass communication. The technology by means of which this communication takes place differs including broadcast media, outdoor media, print media, and internet media communication. Broadcast media like television, radio, film, and recorded music air their information by electronic means. Print media broadcast their information using physical means like a newspaper, book, pamphlet or comics. Outdoor media are a form of mass media that includes billboards, signs, or placards placed within and outside of industrial buildings, shops, sports stadiums, and buses. Internet media communication is the leading mass media by means of Internet technologies for diverse communications in both Internet and mobile networks (Information Security Education \& Awareness, 2016). An Internet media type is a standard identifier utilize on the Internet to specify the kind of data contained in a file. For instance, e-mail clients utilizes them to recognize attachment files; web browsers utilizes them to find out how to display or output files that are not in HTML format, and search engines utilizes them to classify data files on the web. The following are some of the mass communication systems according to Information Security Education and Awareness (2016):

1.2.1. E-Mail Security: The e-mail is an abbreviated form of electronic mail and one of the extensively used mailing services on the Internet. The email is used for transmission 
of messages in a text format over the Internet. The message can be sent by using the receiver e-mail address and vice versa. An e-mail can be sent to any number of users at a time and it takes only a few minutes to reach the destination. The e-mail consists of two parts, namely, the message header which contains control information, an originator's email address, and one or more recipient addresses and message body, which is the e-mail content. Some e-mail systems are confined to a single computer system or to a small network, and they are connected to the other e-mail systems via the gateway, which helps the users to connect to anywhere in the globe. While there are various electronic mail systems which have different formats, there are also some emerging standards such as MAPI, and X.400 that enables the users to send messages in between different electronic mail systems. There is also X.500 which is an extension of X.400 standard, which provides standard addressing formats for sending e-Mails so that all e-mail systems are linked to one another (Information Security Education and Awareness, 2016).

1.2.2. Instant Messaging: Instant messaging is rising because of emerging technologies and Internet speeds and the technological change evident in real-time text-based to realtime of audio, and video communication between two or more individuals linked over the network. Instant message can enable users including media houses to interact with people in a real time. There are several instant message service providers like Yahoo Messenger, Facebook Messenger, AOL, and Google Talk.

1.2.3. Skype Video Communication: Skype helps media organizations and news reporters to reach audiences globally through writings, words, pictures and sounds transmitted in a matter of seconds.

1.2.4. WhatsApp: WhatsApp is one of the well-known messaging apps in the world which enable users to send messages to another individual or group of persons. It is an easy mode of online communication for news reporters to stay in touch with the newsroom and colleagues by exchanging images, video and audio.

1.2.5. Facebook: Many Internet users utilize this social network platform to share their work, crowdsource information, remain connected colleagues and newsmakers, follow companies and news on their beats, subscribe to important people and participate in group discussions.

1.2.6. Twitter: Twitter is a social media platform for following breaking news and sending out breaking news. News reporters can use twitter to team up with others, discover communities, and track trends and topics about world events.

\subsection{Merits and Drawback in Using Mass Communication Systems}

In crisis situations, sending information to the people involved is important, and ought to be done swiftly. With mass communication systems, text alerts or notifications can be sent from a single interface or across multiple platforms. Mass communication systems strengthen people's hope in regard to their expectation of relevant authorities to come to their aid during distressed times as it could guarantee a swift means to provide a secured pathway out of the emergency situation. Thus, mass communication systems can also significantly speed up the entire process of safety. With the access mass communication systems provides to crisis management teams, individuals can appreciate the rapid increase in how fast authorities are alert to potential danger, and how fast volunteers can respond to the crisis. With mass communication systems, reporters can reach a larger number of persons than they could with any other system. With regard to the potential threat, reporters can send detailed communication and notification across multiple platforms. However, one major demerit is that many mass communication systems are 
also means for people to be misguided by erroneous information. While a social media site like Twitter is an internet media environment many turn to in hopes of receiving the latest information, the problem with that lies in how much bogus information can be disseminated through such a platform, hindering overall safety. But a specific trusted notification campaign can effectively minimize the spread of bogus information (Integration Security Systems \& Services, 2017). Given the merits and drawback of mass communication systems, journalism education in Nigeria can be redefined to help combat the spread of misinformation across multiple platforms.

\section{Journalism Education in Nigeria}

Training, which is a mechanism for imparting knowledge and skill, is a major function of every profession, which is normally carried out by an organised body or appropriate institutions established for that purpose. History reveals that in Nigeria, journalism preexisted the establishment of institutions structured to train and produce journalists. When IweIrohin, the first Nigerian newspaper was published in 1859, there was no organised form of training for journalists in any form. Radio broadcasting came into existence in 1932 while television broadcasting started in 1959. There were no formal institutions to feed these media outfits with trained journalists or professionals. Journalism education and training were characterised by the on-the-job training or learning. Formal training of newspaper journalists in Nigeria began 1954 when the University College, Ibadan introduced a two-week vacation course for them(Adaba, 1989), while the training of radio journalists began in 1956 when the news department of the then Nigerian Broadcasting Corporation (NBC) introduced a two-year in-service training them. Later in 1980, the Nigerian federal government established the Television College, Jos for the training of TV journalists. This subsists to say that the foundation, processes, and culture or rules of mass communication in Nigeria was laid by non-professionals. They acquired their experiences through on-the-job training. Armed with formal or basic education, these journalists were embroiled in the spirit of nationalism and anti-colonial struggle. However, the establishment of these institutions created an increasing demand for trained personnel by these media houses. Journalism requires different types of training and skills due to its diverse roles such as photo-journalism, headline and lead writing, foreign correspondence, literary critic, graphic designing, continuity announcer, cartoonist, subeditor, and producer among others (Allan, 2014).

This demand led to the establishment of different institutes for journalists of mass communication training. Their requirements for Journalism education and the pattern of their training are similar worldwide. The needs include an orientation/understanding of one's workplace system and the specialized function of different mass communication fields; a liberal arts and sciences background; basic skills; technical skills; and the ability to learn more(Gaunt, 1992). The training pursues increased professionalism, formalization and standardization of journalism (Obijiofor and Hanusch, 2011; Josephi, 2010). Meanwhile, the University of Nigeria was the first to introduce full degree programme for the training of journalists irrespective of whether it is radio, newspaper, or television in 1960. It began as the Jackson College of Journalism and now Department of Mass Communication, University of Nigeria, Nsukka. The University of Lagos followed in 1967 with their introduction of a one-year practical diploma for working journalists. However, as at 2000 , there were 58 journalism training institutions in Nigeria (Akinfeleye, 2000). This has increased to over 108 training institutions as at 2016.

The massive spread of these training institutions and the quality of outputs of their products has raised the problem and/or question of qualitative education and professionalism among journalists in Nigeria. Journalism education seems to be anchored within wider academic institutional frameworks, which in most cases are at variance with practical experiences in the field of journalism. Experiences show that there is a 
disconnect between journalism training systems and the actual practice in the field (Josephi, 2010). For instance, the training shares universal democratic values but most governments particularly in Nigeria stifle democratic values and press freedom. This has led to the arrests, incarcerations, torture, and extra-judicial killing of journalists (Breit, Obijiofor, and Fitzgerald, 2013).

Consequently, the journalism industry is highly sceptical and do cast aspersion on these graduates' skills, and on the value of university journalism education at large. Consequently, many of these universities or higher institutions of learning that provide journalism education do resort to internships as a key experiential learning component in curricula, which often favour professional skills. This is a form partnerships relationship between mass communication industry and institutions of higher learning. In addition to all these lacunae and in spite of the massive enrolment and output of journalists in higher institutions' journalism education programmes, a significant number of journalists do not have the required knowledge and skills to perform certain foundational duties. Some of these areas include investigative journalism, data-based journalism, enhanced newsroom technology, and digital security. They need specialised training on courses that enable them to acquire such knowledge and skill. Teaching in this type of journalism education prepares students for 'industry-related jobs rather than developing critical-thinking. It requires innovations in the pattern of teaching that 'break down silos and walls' in the physically and mentally spheres, which enables their graduates to serve the society better. Institutional environments in this type of training expose students to practical, which provide knowledge and skills that equip them for better productive working life. This had led to the emergence of specialised Journalism training institutes in many regions of the world like the Germany's Springer Group, German's Konrad Adenauer Stiftung, the U.S.' American Press Institute, South Africa's Institute for the Advancement of Journalism, South Africa Independent Newspapers Training Institute, and the African Woman and Child Feature Service among others. Most of these institutes provide training to working journalists only (Nelson, 2010).

These raise serious questions concerning the higher institutions training methods, capacity, facilities, infrastructure, and who should provide journalism education(Allan, 2014; Berger, 2007).There seems to be a gap between the de jure and de facto roles of journalists in sustaining the development and evolution of socio-economic and political dynamics through the provision of information needed to make policy decisions. This led to the establishment of Mass Communication and Technology Institutes for the training of professional journalists in Nigeria in the $21^{\text {st }}$ century. This paper evaluates this development and its challenges in the light of technological innovations.

Historically, training or education for media workers or journalists started in 1865 at Washington College, which later became Washington and Lee University in Lexington, Virginia - USA. Its founder Robert E. Lee initiated it as one of the post-war reconstruction and rebuilding efforts (Washington and Lee University, 2014). Many other universities and countries, such as the Ecole Superieure de Journalisme of Paris in 1899, the University of Missouri in 1908, and Columbia University of New York in 1912, followed suit(Nordenstreng, 2009). From the $19^{\text {th }}$ century through the $20^{\text {th }}$ to the $21^{\text {st }}$ century, virtually all the universities across the world established study programmes in journalism such as diploma, bachelor degree, masters, and $\mathrm{PhD}$ among others. The Americanisation and/or domination of these programmes by the Global North, which contradicts the great diversity in the social, economic, political, and cultural contexts in which these journalism programmes operate, raised major challenges (Zelizer, 2008). These challenges include epistemological and methodological biases against experiences in the Global South, insecurity, and limited supply of infrastructure (Richards \& Wasserman, 2013).

These challenges were complicated by the emerging and increasing specialization in teaching and research among universities in the Global South that tend to focus on media 
ownership, audiences, and ethics (Sterling, 2009). In this divide, the media is seen as an essential instrument for national development. This led to the emergence of intellectual nationalism that challenges the Americanised journalism education thereby establishing methodological and epistemological orientations that address divergent cultures and experiences. Attempts to harmonise this conflicting orientation led to a move towards international journalism education, which demands modified curriculum, teachers, and methods (Servaes, 2009).

In recent times, there is a progressive increase in university-based programmes that are increasingly transcending national boundaries (Deuze, 2008). This explosive growth of global journalism education attracts private sector involvement in many regions, especially in developing countries. However, this development has been criticised based on the poor quality of its programmes and products, and possible experiences in the exploitation of students. Further, it undermines pre-existing curriculum, programmes, and methods in different institutes of journalism across the Global South, particularly in Nigeria. This inclusive journalism education factors-in issues of gender, cultural and ethnic diversity, which is prevalent in the Global South, into its curriculum, admissions, and staffing (Hallin and Mancini, 2011; Josephi, 2010). This enables graduates of such system "to select and process information within diverse media systems and environments. Their perceived professional roles offer unique insights into the role a country assigns the media - a reflection of its deepest values" (Hanitzsch and Maximilians, 2013, p. 1). However, the most recent challenge to journalism education is the prevailing innovations in technology and their use in journalism. Previous journalism educators, education curriculum and programmes are bereft of Information and Communication Technology education, skills acquisition, and use. Teachers in the various institutes of journalism feel threatened by this development. Thus, scholars, publics, journalists and thus journalism educators have had to reconsider their approaches, definitions and function in society (Deuze, 2000, p. 137). These challenges point to the fact that new journalism educational curriculum, staffing and training are needed.

Furthermore, the primary goal of the education is, "to provide students and the larger society with a deeper understanding of mass communication processes and to improve the practices and performance of mass media professionals" (Association for Education in Journalism and Mass Communication Task Force, 2000, p.2). Summarising this and using Nigeria as a reference point, Akinfeleye (2003:15) observed that the primary aim of journalism education is:

... to train journalists, educate them
and make them responsible and
useful citizens of Nigeria as they use
journalistic expertise to build a new
Nigeria especially in our
developmental efforts in which the
role of mass media had been
recognised by government as a
necessary but not sufficient social
force towards nation-building and
maturity.

Nevertheless, Weaver and Willnat(2012), Josephi(2010), and Greenberg, (2007) among others observed the following broad goals and missions of journalism education:

i. To improve students' knowledge of media programmes;

ii. To provide support to media professionals towards the achievement of better information delivery;

iii. To impart analysis and critical thinking ability and skills to journalists;

iv. To impart modern practical knowledge and skills to journalists; 
v. To indoctrinate journalists into the philosophy of the mass media and dedication to the public service;

vi. To strengthen journalism education by training future educators or teachers in the system;

vii. To build journalist that can address the rapid technological prone changes in mass communication;

viii. To bestow professionalism in journalism and its practices;

ix. To bring innovations and reshape the media systems and patterns of journalism;

$\mathrm{x}$. To provide middle and higher level manpower for mass communication requirements;

xi. To address the problem of knowledge and skills deficiencies in the journalists; and

xii. To impart the technical skills for selecting and processing of news into journalists.

Journalism education in Nigeria started in the form of on the job training wherein people employed as journalist and broadcasters albeit untrained acquire their professional training simply by doing the job and learning from mistakes and consequences. The focus of this form of training was on practical knowledge and skills. This focus was pursued with the introduction of formal institutional training of journalist at the University of Nigeria in 1961. The University replicated the curriculum of the American Jackson College of Journalism whose thrust of communication education was practical skills /training(Oso, 2012)

However, Journalism and mass communication are evolving fast and changing in styles, skills, method, and consumption due to technology and societal transformation. These changes have continued to alter the gaols, nature, programmes and curriculum of journalism education in Nigeria due to media convergence. The general goal at this point, which the curriculum pursues, is the inculcation of certain competencies on trainee journalists. These competencies include general knowledge and intellectual ability; professional techniques for research, writing, editing, design and production; using the tools of journalism and to adapt to new technologies and innovative practices; professional understandings, including ethics; identify the role and legal limitations of journalists in society; and knowledge of best practices in journalism (UNESCO, 2007, p. 30). They provide the basic platform for curriculum contents, which emphasize professional standards such as norms, values, tools, standards and practices of journalism; knowledge; and journalism and society.

The inclusion of these aspects of training and procurement or establishment of the necessary conditions for training forms the basis of government's approval or accreditation of institutes of Journalism education in Nigeria. However, most of these institutes obtain such approval or accreditation without fulfilling these requirements due to bribery and corruption that characterise the operations of the accreditation teams. This weakens the ability of such institutions to deliver their mandates to their students and produce quality graduates.

In addition to this problem, most of the journalism training institutions prefer to and do employ $\mathrm{PhD}$ holders only who do not have any field experiences as teachers or instructors. This, which ignores the appointment of experienced professionals, is to fulfil the basic requirement by the National Universities Commission (NUC) - the organ that regulates institutions of higher learning in Nigeria. This contradicts Declaration No 3 of 2007 of the World Journalism Education Congress (WJEC), which clearly stated that; "Journalism educators should be a blend of academics and practitioners; it is important that educators have experience working as journalists." It is logical therefore that those journalism educators that acquired $\mathrm{PhD}$ but lack industrial experiences, which eliminates the required background for originating and testing theories of journalism and communication. 
These $\mathrm{PhD}$ or non-professional teachers do not have the flair for appropriating and acquiring the appropriate and modern training infrastructure for journalism training. In most cases, they lack the knowledge of their mechanisms and operations. Nevertheless, it is clear that without those infrastructure and training with them, graduates of journalism or mass communication will be illiterates in the field of actual practice without further training. Most of the times, students do not see, nor interact with basic journalism equipment until their internships and/or on-the-job training. It is clear therefore that journalism education requires a synergy between the industrial experiences and the institutional or academic programmes. The pursuit of this agenda in Nigeria led to the evolution and establishment of Institutes of Mass Communication and Technology in Nigeria.

\section{Mass Communication Institutes in Nigeria}

The establishment of the Institutes of Mass Communication and technology in Nigeria was orchestrated by the need to synergise the academic and practical aspect of journalism in order to satisfy the constantly changing needs of the media industry (Odunlami, 2014; Knight, 2012). Such institutes must constantly interact with journalism industry to fashion out acceptable exchanges between them in terms of personnel i.e. their products, sponsorship, studentship, and media contents/curriculum. They connect the newsroom and the classroom symbiotically that both exchange their products to sustain the other (Seelig, 2010). Examples of such institutes include:

i. The Nigerian Institute of Journalism: The Nigerian Institute of Journalism was established in 1963 by the International Press Institute. It is a Diploma awarding mono-technic institute located at Ijaye road, Ogba in Ikeja, Lagos State. A provost - the chief academic officer, a deputy provost, and the registrar constitute the administrative structure of the institute. They drive development, review, and enforcement of its corporate goals and objectives.

ii. The Nigerian Institute of Journalism: This institute was established in 1963 by International Press Institute (IPI) - an international professional organization of media executives, and located in Lagos. The primary goals of IPI are press freedom and professionalism among practitioners worldwide. Although shut down by 1964-70 political crisis and civil war, the institute was re-established on October 12, 1971, by the Newspaper Proprietors Association of Nigeria (NPAN) and the Nigerian Guild of Editors. It is a non-profit making institute that is owned and managed by the following media professional association: Newspaper Proprietors Association of Nigeria, Nigerian Guild of Editors, Nigerian Union of Journalists, News Agency of Nigeria, Broadcasting Organisation of Nigeria, Advertising Practitioner Council of Nigeria, and the Nigerian Institute of Public Relations. It is a mono-technic diploma awarding institute with the primary objectives of fostering a free and democratic, just and egalitarian, strongly united and self-reliant society. It trains the minds of prospective students to understand the world around; develop critical thinking and professionalism, ethical standards in research and academic productivity with sound character; and to acquire appropriate skills, abilities and competence for the development of the society.

iii. The International Institute of Journalism: This is a professional Institute for the training of journalists, which is located at Area 11, Garki, Abuja - Nigeria. It is affiliated to the University of Maiduguri to offer training and academic certificates in Journalism, Public Relations/Advertising, Computer Studies, French, and Arabic studies. A chairman and members of a Board together with a Director and Registrar appointed by the Board constitute the administrative structure of the institute. 
iv. The FRCN Training School: This Institute, which is located at No 1a Adekunle Fajuyi Street, Ikeja GRA, Lagos state - Nigeria, was established by the Federal Radio Corporation of Nigeria to provide training for radio broadcasting for government and private broadcasting stations, as well as individuals that are interested in radio broadcasting. It was established in 1957 with the primary goal of training broadcasters, news writers, engineers and technicians etc for better performance in the media industry.

v. NTA Television College: This Institute was established in 1980 and located in Jos, Plateau state. Its management team include a Rector, Registrar, and Board directors. Its primary goal is to provide short proficiency courses exclusively to the staff of Nigerian Television Authority. However, it expanded its programmes to award diploma and BSc. degree certificates for people desiring training on television broadcasting alone. Affiliated to Ahmadu Bello University (ABU) Zaria in 2006, the institute offers training in three special areas, namely: Television Journalism, Television Production, and Television Engineering.

The scopes of these three areas of study were covered in the various curricula drawn and used by different departments of the institute. Nevertheless, they pursue training and development services on computer facilities using state of the art technique and course modules, modern skills in digital studio management, broadening the knowledge of participants in areas other than their core discipline, specialised reporting, industrial Relations, conflict reporting,application of Media Laws and Ethics, and basic skills like creative writing,research efforts at various vocal expressions, programme planning, resource management, news psychology, sourcing, scripting and presentation.

vi. Kano Journalism Institute: This Institute was established by Kano state government and affiliated to Northwest University to award Certificates and Advanced Certificates in journalism and media communication. Its primary objectives are to develop the capacities of pressmen and inculcate into them the best practices in journalism. Its management team is headed by a Director.

vii. Digital Media Institute, Lagos Nigeria: This is a pioneer digital Media Institute in Nigeria temporarily located at No.6 Edmund Street NIMR, Off Murtala Muhammed Way Yaba, Lagos - Nigeria. Its primary objectives are to prepare and equip journalists professionally for the evolving revolutionary, digital media communication, marketing and development. Its curriculum of study is a synergy of field experiences or practice and academic theory. The management team of the institute known as Board/Faculty consists of top-level International Development, Academics, and Marketing Communications industry. They include among others Bunmi Makinwa (Ex-Africa Regional Director of United Nations Agencies), Prof Ralph Akinfeleye(Department of Mass Communication, University of Lagos), Prof Kate Omenugha (Department of Mass Communication, Nnamdi Azikiwe University), Azubuike Ishiekwene(former Editor, Punch Newspaper), Lekan Otufondurin(Online Editor, The Nations), and Dr Victor Ogwezzy (CMO, Daily Independent). Their institutional programmes are one month weekend intensive classes, in-plant/in- house module mobile classes, and crash programmes for busy professionals.

Nigerian Institute of Journalism is the foremost professional and academic Institution for the training and retraining of contemporary Journalists and media and Communication professionals that can meet the challenges of the 21st Century and beyond, with the vision of 'raising a new crops of journalists and communication experts, who will uphold the ethics and professional values of media and communications practice'. The Institution is committed to academic and professional excellence in media practice and the development of the Nigeria media industry. 


\section{Conclusion}

Journalism education and Internet mass media in Nigeria can be strengthened through improved mass communication systems and network security. The inability of universitytrained media professionals to provide expected or desired services, which would have solved the prevailing problems of journalism in Nigeria, have led to the emergence of several media institutes in the country. Currently, there are more than seven of such institutes. Initially, these institutes emerged to provide experiential training to already employed academic professionals who could not meet up with their responsibilities in the field, and to unprofessional journalists that need required theoretical exposition to foster the development of media industry in Nigeria. However, most of these institutes have evolved developmentally to offer training to individuals who are not employed but who seek such training to enable them secure jobs. This led to their awarding of diploma and degree certificates and to the affiliation of most of them to Nigerian University Commission's approved universities. This affiliation and/or academic collaboration with universities legitimizes their certificates and ensures sustained academic provisions. This paper, thus, recommends further studies on the effectiveness of journalism education in relation to mass communication systems, multimedia journalism, the problems and needs of media institutes, network security of the Nigerian media, and improved digitalisation of journalism education and mass communication systems in Nigeria.

\section{References}

[1] W. J. Allan, "An Evaluation of Training Standards in Kenyan Media Colleges: A Case Study of Public and Private Middle-Level Media Training Colleges in Nairobi", IOSR Journal of Humanities and Social Science, vol. 19, no. 2, (2014), pp. 68-83.

[2] R. Breit, L. Obijiofor and R. Fitzgerald, "Internationalization as de-Westernization of the Curriculum: The case of Journalism at an Australian University", Journal of Studies in International Education, vol. 17, no. 2, (2013), pp. 119-135.

[3] M. Deuze, "Global Journalism Education: A Conceptual Approach”, Journalism Studies, vol. 7, no. 1, (2008), pp. 19-34.

[4] S. Greenberg., "Theory and Practice in Journalism Education", Journal of Media Practice, vol. 8, no. 3, (2007), pp. 289-303.

[5] D. Odunlami, "Journalism and Mass Communication Education in Nigeria: in Search of the Right Pedagogy", Journal of Literature, Languages and Linguistics, vol. 3, (2014), pp. 45-49.

[6] M. Seelig, "Journalism and Mass Communication Education: The Impact of Technology on Pedagogy", Explorations in Media Ecology, vol. 9, no.4, (2010), pp. 245-258.

[7] J. Servaes, "Communication Policies, Good Governance and Development Journalism", Communicatio: South African Journal for Communication Theory and Research, vol. 35, no. 1, (2009), pp. 50-80.

[8] B. Zelizer, "How Communication, Culture, and Critique Intersect in the Study of Journalism", Communication, Culture \& Critique, vol. 1, no. 1, (2008), pp. 86-91.

[9] G. Berger and C. Matras, "Criteria and Indicators for Quality Journalism Training Institutions \& Identifying Potential Centres of Excellence in Journalism Training in Africa", UNESCO, Paris, (2007).

[10] P. Gaunt, "Making the Newsmakers: International Handbook on Journalism Training", Greenwood Press, Westport, CT, (1992).

[11] D. C. Hallin and P. Mancini, "Comparing Media Systems Beyond the Western World", Cambridge University Press, Cambridge, (2011).

[12] B. U. Josephi, "Journalism Education in Countries with Limited Media Freedom", Peter Lang, New York, NY, (2010).

[13] L. Obijiofor and F. Hanusch, "Journalism across cultures: an introduction", Palgrave Macmillan, New York, NY, (2011).

[14] UNESCO, "Series on Journalism Education. Model Curricula for Journalism Education", UNESCO, Paris, (2007).

[15] D. H. Weaver and L. Willnat, "The global journalist in the $21^{\text {st }}$ century", Routledge, New York, NY, (2012).

[16] A. T. Adaba, "Harmonising Training and Research within National Communication Objectives", Edited N. Uvieghara, Centre for Black and African Arts and Civilization, Lagos, vol. 1, (1989), p. 235.

[17] K. Nordenstreng, "Conclusions: Soul-searching at the Crossroads of European Journalism Education", Edited G. Terzis, Intellect, Bristol, (2009), pp. 511-517.

[18] R. A. Akinfeleye, "Proliferation of Journalism Mass Communication Training Institutions in Nigeria and its Impact on Professional Standards in media and Democracy", A Report of Workshop on 
Democracy and the Media, Nigerian Press Council Centre for International Media Assistance, Washington DC, (2000), May 21-23.

[19] R. A. Akinfeleye, "Fourth Estate of the Realm or Fourth Estate of the Wreck: Imperative of Social Responsibility of the Press", University of Lagos Inaugural Lecture, UNILAG Press, (2003), pp. 10-32.

[20] T. Hanitzsch and L. Maximilians, "Role perceptions and Professional Values Worldwide", Report presented to the WJEC Syndicate Group, Mechelen, Belgium, (2013), July.

[21] L. Oso, "Press and Politics in Nigeria: On Whose Side?", LASU Inaugural Lecture Series, 47th Ed., (2012), pp. 2-40.

[22] Cisco, "What Is Network Security?", https://www.cisco.com/c/en/us/products/security/what-is-networksecurity.html, (2018) March 20.

[23] Information Security Education \& Awareness, "Internet Communication Media", March 20. http://www.infosecawareness.in/infosec-concept/internet-communication-media, (2016).

[24] Integration Security Systems \& Services, "The importance of mass communication systems", March 15, https://www.s3integration.com/blog/importance-mass-communication-systems/, (2017). 